\title{
A novel silk fibroin-supported iron catalyst for hydroxylation of phenol
}

\author{
Bahar Başak Pekşen, Caner Üzelakçil, Alev Güneş, Özge Malay and Oguz Bayraktar*
}

\author{
Bioreaction Engineering Laboratory, Department of Chemical Engineering, Izmir Institute of Technology, Gülbahçe Köyü, 35430, Urla-Izmir, \\ Turkey
}

\begin{abstract}
The aim of this study was to explore the potential use of silk fibroin (SF) as a catalyst support material for phenol hydroxylation reactions. Iron-substituted silk fibroin fibers were prepared using formic acid at room temperature and characterized using inductively coupled plasma atomic-emission spectrometry, scanning electron microscopy, Fourier transform infrared spectroscopy (FTIR) and optical microscopy. Measurement of an FTIR spectrum showed that the secondary structure was $\beta$-structure before and after iron substitution. To evaluate the catalytic properties of prepared catalyst, phenol hydroxylation reaction was carried out using aqueous hydrogen peroxide as an oxidant. An excellent transformation of phenol into dihydroxybenzenes (catechol and hydroquinone) was achieved. Phenol conversions of $3.3 \%, 61.2 \%$, and $80.3 \%$ were obtained at room temperature, $40^{\circ} \mathrm{C}$ and $60^{\circ} \mathrm{C}$ respectively. It was found that no further phenol conversion proceeded because catalysts became separated from the reaction system during the reaction. No significant leaching of the iron was detected. Catalyst could be reused several times without a significant change in activity. Parent silk fibroin fibers without iron were inactive.
\end{abstract}

(C) 2006 Society of Chemical Industry

Keywords: silk fibroin; phenol hydroxylation; Fe(III); hydrogen peroxide; diphenols

\section{INTRODUCTION}

The hydroxylation of phenol is industrially a very important reaction, since it produces diphenols (e.g., hydroquinone and catechol), which are important starting materials in the production of chemicals used as agrochemicals, pharmaceuticals, flavors and aromatic essences. Hydroquinone is used as an intermediate to produce antioxidants for rubber, food and pharmaceuticals. Catechol is used as rubber hardening agent, electroplate additive, skin preservative as well bactericide.

$\mathrm{H}_{2} \mathrm{O}_{2}$-based catalytic hydroxylation can be environmentally as well as economically very favorable because $\mathrm{H}_{2} \mathrm{O}$ is formed as the only by-product. $\mathrm{H}_{2} \mathrm{O}_{2}$ has high content of active oxygen and is rather inexpensive compared to various organic peroxides and peracids. Hydroxylation of phenol with hydrogen peroxide using water as the reaction solvent is mainly performed for producing diphenols in an environmentally friendly way. ${ }^{1-5}$

Homogeneous catalysts such as mineral acids, metal ions and metal complexes are difficult to separate and recover from the reaction mixture, which prevents their practical utilization. Therefore, numerous heterogeneous catalysts such as metal oxides, ${ }^{1}$ metal complex oxides, ${ }^{2,3}$ encapsulated metal complexes ${ }^{4,5}$ and hydrotalcite-like compounds ${ }^{6}$ have been studied. Although activated carbon and oxides (alumina, silica, zeolites) are the most used supports, polymeric supports have recently attracted considerable attention for their low cost, ease of preparation, catalyst recycling, and versatile conditioning. ${ }^{7,8}$ Many researchers have focused studies on applying polymers as the matrices for dispersing metallic centers. ${ }^{9}$ Specific properties of polymers, such as their ability for stabilization of finely dispersed metallic nanoparticles, swelling of polymer matrix and changing reactivity of catalysts due to various hydrophobic/hydrophilic characters, make polymeric carriers very attractive as potential supporting materials. Supporting catalytic metals on specially tailored supports can add new functionalities such as reaction enantioselectivity. Biopolymers have been extensively studied during the past decade for chiral separation. For this reason, interest is now focusing on the use of biopolymers as supports for catalysis. ${ }^{10}$ Practically all classes of natural biopolymers such as silk, ${ }^{11-18}$ starch, cellulose and chitosan have been investigated as supports for metal complexes. ${ }^{7}$

Chitosan and silk fibroin have been used as catalytic supporting materials. Recently, research into supported catalysis has been carried out on chitosan. ${ }^{19-21}$ The main characteristics of this biopolymer are its high amine group content and its cationic behavior in acidic solutions. The presence of amine groups leads to interesting chelating properties for metal

* Correspondence to: Oguz Bayraktar, Bioreaction Engineering Laboratory, Department of Chemical Engineering, Izmir Institute of Technology, Gülbahçe Köyü, 35430, Urla-Izmir, Turkey

E-mail: oguzbayraktar@iyte.edu.tr

(Received 29 July 2005; revised version received 22 September 2005; accepted 7 December 2005)

Published online 26 May 2006; DOI: 10.1002/jctb.1519 
cations. Chitosan-supported palladium catalyst was studied for chlorophenol dehalogenation ${ }^{19}$. On the other hand, utilization of silk fibroin-supported zerovalent metal catalyst for asymmetric hydrogenation was reported by Akabori and co-workers during 1956 to $1961 .^{11-14}$ More recently, a core-shell nanostructured gold colloid-silk fibroin bioconjugate was reported by Zhou et al. ${ }^{15}$ and, lately, silk fibroinsupported palladium catalyst has been studied for chemoselective hydrogenation. ${ }^{16-18,22}$

Silk fibroin is an attractive natural fibrous polymer produced by the species Bombyx mori. ${ }^{23,24}$ It is known that besides material for clothing, fibroin has also been investigated as one of the promising resources of biotechnology and biomedical materials. ${ }^{25}$ Another important reason for interest in this material is its versatility. ${ }^{26}$ It can be conditioned in forms as different as beads, powder, films, sponges, gels, fibers, membranes and hollow fibers, or as a coating material on mineral membranes that may be helpful in the design of new catalytic systems. The total content of glycine, alanine, serine and tyrosine comprised more than $90 \mathrm{~mol} \%$ of the whole volume of the silk fibroin, and very few residues of sulfur amino acids, which can be a strong catalyst poison of metals, are included. ${ }^{17}$ The fibroin macromolecules are closely packed owing to higher content of hydrophobic residues as compared to that of hydrophilic polar groups. Fibroin sparingly swells in water and is soluble in concentrated solutions of $\mathrm{LiCNS}, \mathrm{LiBr}, \mathrm{CuCl}_{2}$, $\mathrm{Ca}(\mathrm{CNS})_{2}$, and $\mathrm{ZnCl}_{2}$, copper ammonia solution $\left(\mathrm{CuSO}_{4}+\mathrm{NH}_{4} \mathrm{OH}\right)$, phosphoric acid, and some other inorganic solvents. ${ }^{27}$ Although several organic solvents have been tried to obtain stable protein solution, formic acid is known as a good solvent at present because this solvent allows producing a stable solution and has an excellent film and fiber formation properties for silk protein polymer. ${ }^{28}$

The powdery form of supported catalysts often becomes a great problem for practical uses in fine chemicals synthesis. Hence, much research has been directed at immobilizing catalyst powders on a carrier material for convenient handling. We have studied the preparation and catalytic application of iron loaded silk fibers. Catalytic silk fibers were successfully prepared by a simple technique. To the best of our knowledge, no report concerning the use of silk fibroin supported iron catalyst for the hydroxylation of phenol has been published in the literature. The aim of the present paper is to explore the application of silk fibroin as catalyst support material for phenol hydroxylation reactions.

\section{EXPERIMENTAL Materials}

The native silk of Bombyx mori (domestic silkworm) was obtained in reeled form from the Silk Industry Research Center, Bursa, Turkey. Nitrate of Fe(III), phenol, hydroquinone, catechol, hydrogen peroxide
(30\%) and formic acid were purchased from SigmaAldrich. Other reagents and solvents used were HPLC grade and obtained from Sigma-Aldrich.

\section{Catalyst preparation}

The raw silk fibers of Bombyx mori were processed three times ( $40 \mathrm{~min}$ each) in $0.5 \mathrm{wt} \% \mathrm{Na}_{2} \mathrm{CO}_{3}$ solution at $98-100^{\circ} \mathrm{C}$ to remove sericin (degumming), rinsed with deionized water, and dried at room temperature. The degummed fibroin $(1 \mathrm{~g})$ was dissolved in $50 \mathrm{~mL}$ of formic acid (98\%), by stirring at $30^{\circ} \mathrm{C}$ for $2 \mathrm{~h}$. The ratio of degummed silk to formic acid was always kept at 1:50 (weight/volume). Iron nitrate $(0.5 \mathrm{~g})$ was added to the prepared solution and mixed for another $2 \mathrm{~h}$. The resulting solution was poured into Petri dishes with a diameter of $10 \mathrm{~cm}$ and left under the fume hood to dry. After drying the prepared iron containing fibroin fibers was washed several times with deionized water in order to remove excess iron.

\section{Catalyst characterization}

Morphology of the catalyst samples was observed using an optical microscope (Olympus C-4040). Scanning electron micrographs were recorded on a Philips XL $30 S$ FG. Infrared spectra in the region $400-4000 \mathrm{~cm}^{-1}$ were recorded in $\mathrm{KBr}$ pellets using a Shimadzu 8101 FT-IR spectrophotometer. The iron content of the catalyst was determined by an inductively coupled plasma spectrometer (ICP, Varian 8410). Standard solutions for ICP calibrations were prepared by using ICP multi-element standard solution. A digestion procedure (contact of the catalyst with $65 \%$ nitric acid) was used to disrupt the support and dissolve the iron.

\section{Phenol hydroxylation and analytical methods}

Phenol hydroxylation was carried out in a three-necked flask $(250 \mathrm{~mL})$ equipped with a magnetic stirrer, reflux condenser and temperature controller. First, $0.2 \mathrm{~g}$ of phenol was dissolved in $100 \mathrm{~cm}^{3}$ deionized water (initial phenol concentraion $=0.021 \mathrm{~mol} \mathrm{dm}^{-3}$ ), then a certain amount $(0.1 \mathrm{~g})$ of catalyst was added to the flask. After heating the mixture containing phenol solution and catalyst to the desired reaction temperature, an appropriate amount of $30 \mathrm{wt} \%$ aqueous $\mathrm{H}_{2} \mathrm{O}_{2}$ was added for the required phenolto-hydrogen peroxide molar ratio of 1 and the reaction was started. The reaction was monitored by taking aliquots at different time intervals. Immediately after sample collection, vials containing reaction mixture were covered with aluminum foil to protect them from light. Samples from the reaction mixtures were analyzed by high-performance liquid chromatography (HPLC). An Agilent 1100 HPLC system equipped with a reversed-phase $C 18$ column $(250 \mathrm{~mm} \times 4.6 \mathrm{~mm}$ i.d., $5 \mu \mathrm{m}$ particle sizes, Lichrospher ${ }^{\circledR}$ ) was used for HPLC analysis. Aliquots of $20 \mu \mathrm{L}$ were injected and separation was carried out with an isocratic mobile phase consisting of methanol-water $(60: 40, \mathrm{v} / \mathrm{v})$ with a flow rate of $1 \mathrm{~cm}^{3} \mathrm{~min}^{-1}$ and at $30^{\circ} \mathrm{C}$ column 
temperature. The detection wavelengths were $280 \mathrm{~nm}$ for detecting phenol, catechol, and hydroquinone. Prior to injection of a sample, the column was equilibrated with the mobile phase at a flow rate of $1 \mathrm{~cm}^{3} \mathrm{~min}^{-1}$ for at least $20 \mathrm{~min}$ or until a steady baseline was obtained. The percentage of each compound in the reaction mixtures was estimated directly from the corresponding peak areas.

\section{Leaching tests}

To test if metal ions were leaching out from the catalyst, the fiber catalyst was removed from the hot reaction mixture. Then the reaction mixture was monitored by HPLC analysis to check the progress of the reaction by leached metal ions, if any. The leaching test of the prepared catalyst was also evaluated by digesting the reaction mixture after each reaction completion. The reaction mixture was digested in a Teflon beaker by the addition of $\mathrm{HNO}_{3}$ after all the organic solvent was completely evaporated. Metal contents of digested residue for all catalysts were determined using inductively coupled plasma (ICP) technique.

\section{RESULTS AND DISCUSSION Catalyst characterization}

Photographs of fibroin fibers without iron loading and with iron loading are given in Fig. 1(a) and (b), respectively. With iron loading the color of fibers changed to red-brown, as expected. As seen from Fig. 1(b), color changes throughout the fiber showed that iron content of fibers was not evenly distributed. Sufficient mixing during catalyst preparation and drying stages could overcome this problem. Using optical microscopy, we studied the changes in color and texture of these fiber catalysts. Figure 1(c) shows one example of the polarized light optical microscopy pictures of iron-loaded fibers. The data showed that a sample with no added iron has a dull texture that did not reflect light very well. Fibers with iron appeared to acquire a 'glassy' cover which, under optical microscopy, gave fibers a sharper definition and glossy appearance, making them more reflective to light. Increasing levels of iron on fibers further enhanced the observed glassy layer and, as expected, changed the particle colour to red-brown, similar to the familiar color of iron oxide. Only the color changed, from white, to a light ferric oxide red/brown and finally to a darker red-brown.

Scanning electron microscopy (SEM) images evidenced the fibrous structure and the smooth surface of the fibroin fiber catalyst (Fig. 2a, b). The iron dispersion was attributed to an interaction between the iron and amino acids of the silk fibroin, increasing the resistance to growth of the iron cluster.

Figure 3 shows the FTIR spectra of fibroin fiber before (Fig. 3a) and after iron loading (Fig. 3b). It

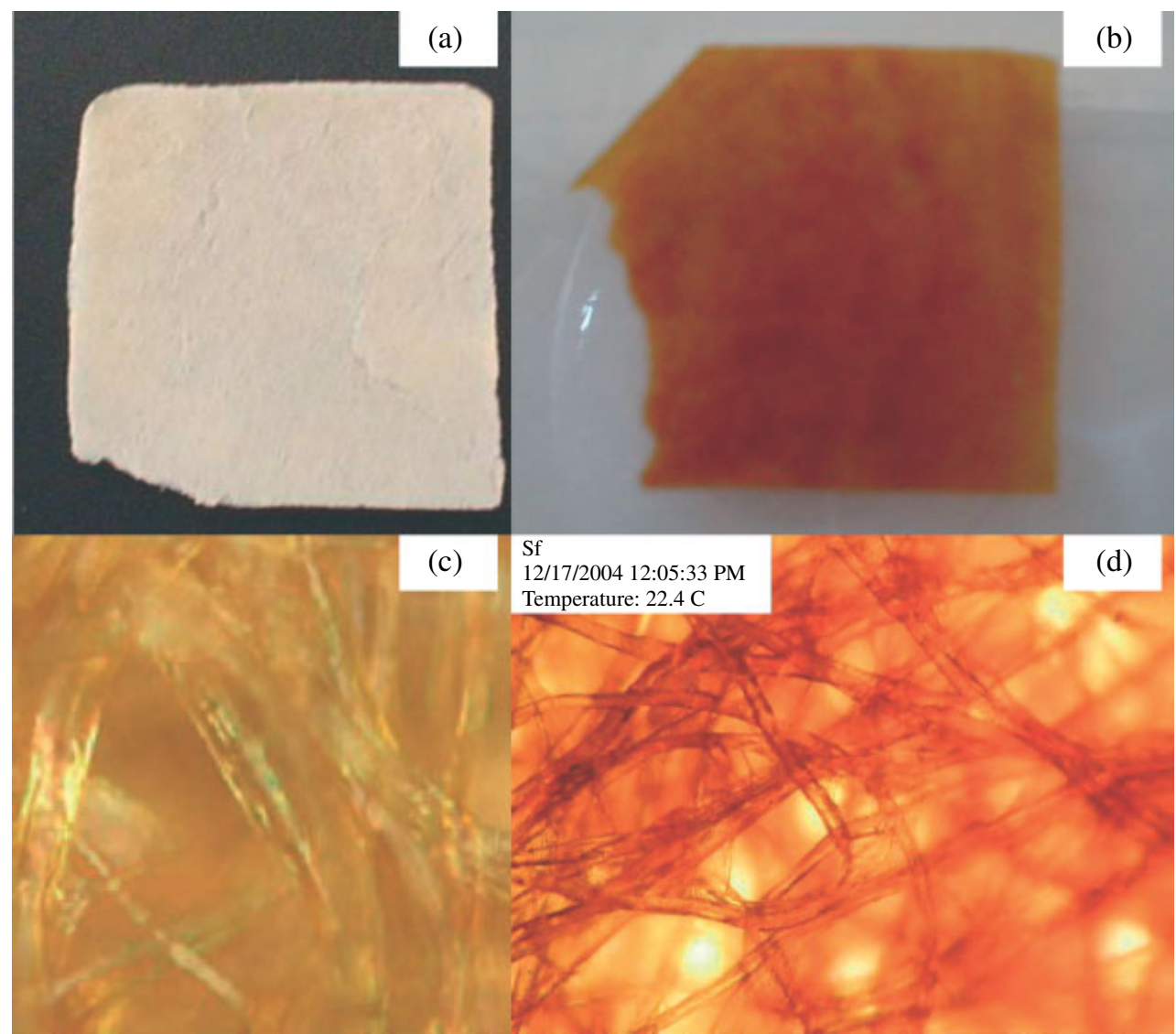

Figure 1. Photographs of silk fibroin fiber without iron (a), and with iron (b), polarized light microscopy image (c) and optical microscopy image of fibroin fiber with iron (d). 

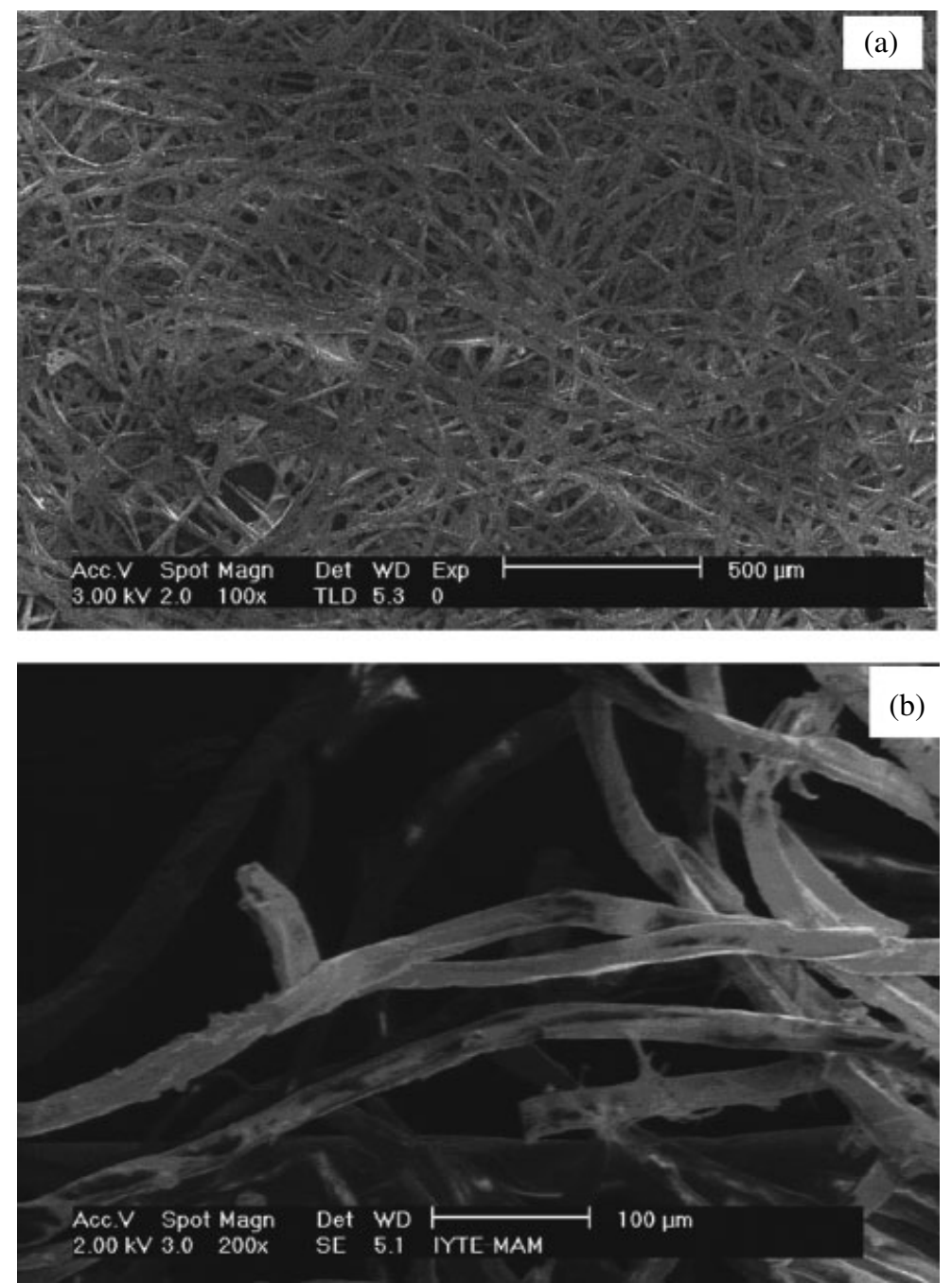

Figure 2. SEM micrographs of fibroin fiber catalyst at $\times 100$ (a) and $\times 200$ (b) magnifications.

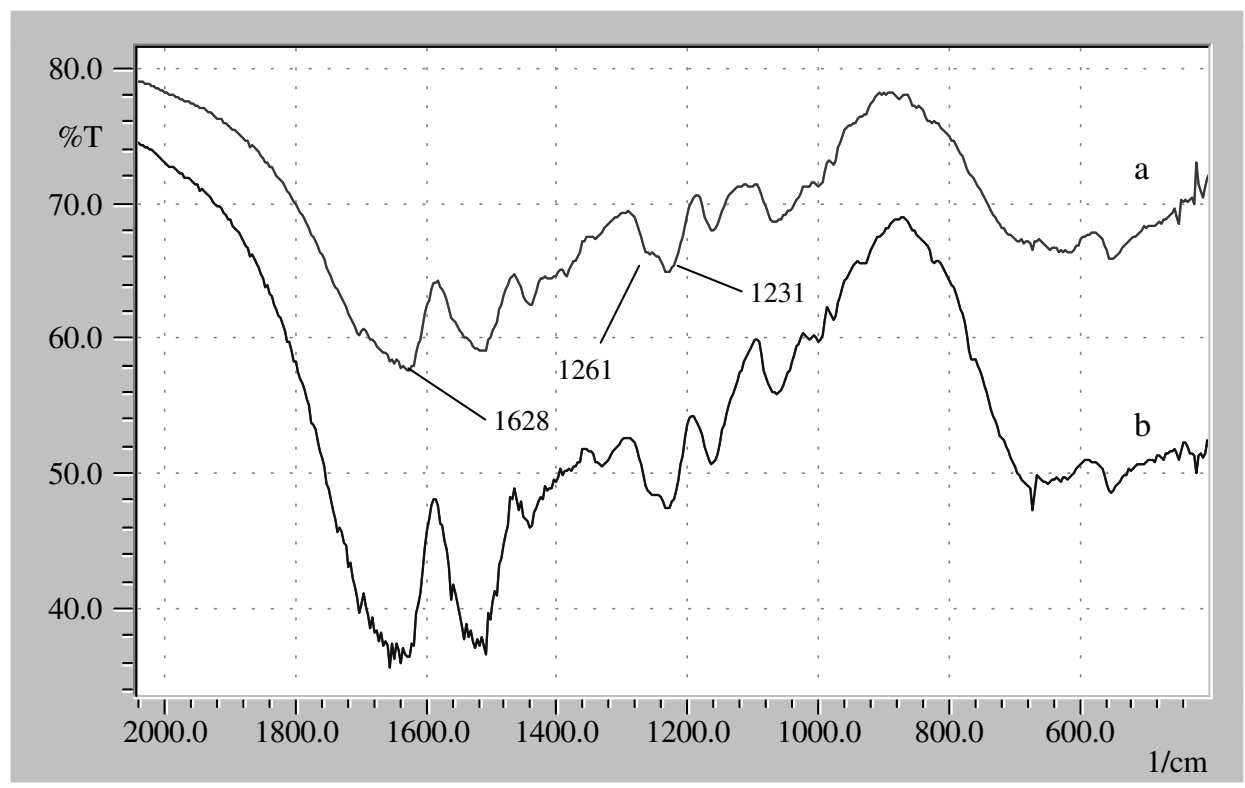

Figure 3. FTIR spectra of fibroin fiber (a) without iron (b) with iron loading.

was well established for fibroin and other proteins that the peak position of the absorption frequency was quite sensitive to the secondary structure. Absorption bands at 1628 (amide I), 1533 (amide II), and $1261 \mathrm{~cm}^{-1}$ (amide III) were assigned to the $\beta$-sheet conformation. Both spectra before and after iron loading were 
apparently ascribable to the $\beta$-sheet structure. There was no structural changes caused by iron loading by analyzing the amide I, II, III bands in IR spectroscopy. This result suggested that no conformational change of fibroin fiber occurred from the $\beta$-sheet to random coil structure due to iron loading. The insolubility property and crystal structure findings were consistent with the literature. ${ }^{28}$

\section{Phenol hydroxylation}

The catalytic hydroxylation of phenol usually gives two products: catechol and hydroquinone. These products are the only expected ones, as the $-\mathrm{OH}$ group of phenol is ortho and para directing. The reaction simply adds a new $-\mathrm{OH}$ group to the molecule. In this study, catechol and hydroquinone were the major products of phenol hydroxylation reaction using $\mathrm{H}_{2} \mathrm{O}_{2}$ as oxidant and using the iron loaded fibroin fiber catalysts. Minor product, if any, was not detectable in HPLC under the conditions used here. Table 1 summarizes the results of phenol hydroxylation with $\mathrm{H}_{2} \mathrm{O}_{2}$ over silk fibroin-supported iron catalysts in powder and fiber form. There was only a small difference in the activities of the powder form and fiber form, as both catalysts contained $4.4 \mathrm{wt} \% \mathrm{Fe}$. For both types of catalysts, catechol and hydroquinone were produced as major products. A high selectivity toward catechol was detected for the $\mathrm{Fe}-\mathrm{SF}$ catalysts. A plausible explanation for the above experimental results of phenol hydroxylation was that iron sites in all the iron-containing solid samples were mainly responsible for the heterogeneous phase transformation of phenol into catechol and hydroquinone under the selected reaction conditions. The phenol conversion increased from $61.2 \%$ to $80.3 \%$ with increasing temperature from $4060{ }^{\circ} \mathrm{C}$, while a low activity $(3.3 \%)$ of phenol hydroxylation was observed at $25^{\circ} \mathrm{C}$.

When using a supported metal catalyst a crucial issue is the reusability of the catalyst. The $\mathrm{Fe}-\mathrm{SF}$ fiber catalyst was therefore tested for recoverability and reusability over successive runs. After each run, the original $\mathrm{Fe}-\mathrm{SF}$ catalyst was removed, washed several times with water, and reused under the same reaction conditions as for the initial run without any regeneration. Results from Table 1 showed that the $\mathrm{Fe}-\mathrm{SF}$ catalyst could be recovered and reused in further reaction without a significant decrease in activity. Although the catalytic activity was gradually diminished, a conversion of $57 \%$ was still achieved in the second run, and $51 \%$ conversion was achieved in the third run. It was found that, with recycling of the catalysts, catechol selectivity increased along with a slight decrease in hydroquinone selectivity. This might be due to higher iron content in the catalyst, which was probably lost after each catalyst recycling. Another point of great concern for most anchored catalysts is the possibility that some active metal migrates from the solid support to the liquid phase and that this leached metal would become responsible for a significant part of the catalytic activity. After the first and second runs, reaction samples were analyzed with the inductively coupled plasma atomic-emission spectrometry (ICPAES) technique. No significant amount of iron was determined within the detection limit of ICPAES. Therefore, metal leaching could not be the direct reason for the decrease in yield. The decrease in catalytic activity could be attributed to catalyst deactivation since the color of fibers became darker compared to its initial color. In order to determine whether leaching was a problem, another experiment was performed to estimate the contribution of leached iron to the catalytic activity by performing a filtration during the course of the reaction to remove the solid phase. If the catalytic reaction continued, this would indicate that the active species was leached metal rather than the supported catalyst. Thus an experiment using fiber catalyst (Fig. 4) under the same reaction conditions as given in Table 1 was interrupted after $5 \mathrm{~min}$. The hot aqueous phase without the catalyst

Table 1. Conversion and selectivity in the liquid-phase hydroxylation of phenol with $\mathrm{H}_{2} \mathrm{O}_{2}$ in the presence of iron-loaded silk fibroin ${ }^{\mathrm{a}}$

\begin{tabular}{|c|c|c|c|c|}
\hline \multirow[b]{2}{*}{ Catalyst type } & \multirow[b]{2}{*}{ Temperature $\left({ }^{\circ} \mathrm{C}\right)$} & \multirow[b]{2}{*}{ Phenol conversion (\%) } & \multicolumn{2}{|c|}{ Selectivity (product) ${ }^{\mathrm{b}}(\%)$} \\
\hline & & & Catechol & Hydroquinone \\
\hline Powder & 25 & 3.3 & $100.0(3.3)$ & - \\
\hline Powder & 40 & 61.2 & $64.2(39.3)$ & 35.8 (21.9) \\
\hline Powder & 60 & 80.3 & $57.5(46.2)$ & $42.5(34.1)$ \\
\hline Fiber (1st run) & 40 & 60.0 & $55.0(33.0)$ & $45.0(27.0)$ \\
\hline Fiber (2nd run $\left.{ }^{\mathrm{C}}\right)$ & 40 & 57.0 & $63.8(36.4)$ & $36.2(20.6)$ \\
\hline Fiber (3rd rund) & 40 & 51.0 & $70.6(36.0)$ & $29.4(15.0)$ \\
\hline Fiber (hot filtration ${ }^{\mathrm{e}}$ ) & 40 & 36.0 & 70.7 (25.5) & $29.3(10.5)$ \\
\hline Unloaded fiber & 40 & no activity ${ }^{f}$ & - & - \\
\hline No catalyst & 40 & no activityg & - & - \\
\hline
\end{tabular}

a Reaction conditions: $0.2 \mathrm{~g}$ phenol in $100 \mathrm{~cm}^{3}$ water as solvent, $0.1 \mathrm{~g}$ catalyst, time $=2 \mathrm{~h}$, phenol/ $\mathrm{H}_{2} \mathrm{O}_{2} \mathrm{molar}$ ratio $=1$.

${ }^{b}$ Conversion and selectivity were determined by HPLC. Yield for a specific product can be calculated as conversion $\times$ selectivity.

$\mathrm{c}, \mathrm{d}$ Catalyst thoroughly washed with water and used in a second and third reaction cycles respectively.

e The fiber catalyst was removed from the reaction mixture by hot filtration, after $5 \mathrm{~min}$.

${ }^{f} \mathrm{No}$ catalytic activity was detected without catalyst towards hydroxylation of phenol.

9 No catalytic activity was detected with fibroin fiber containing no iron as support material. 


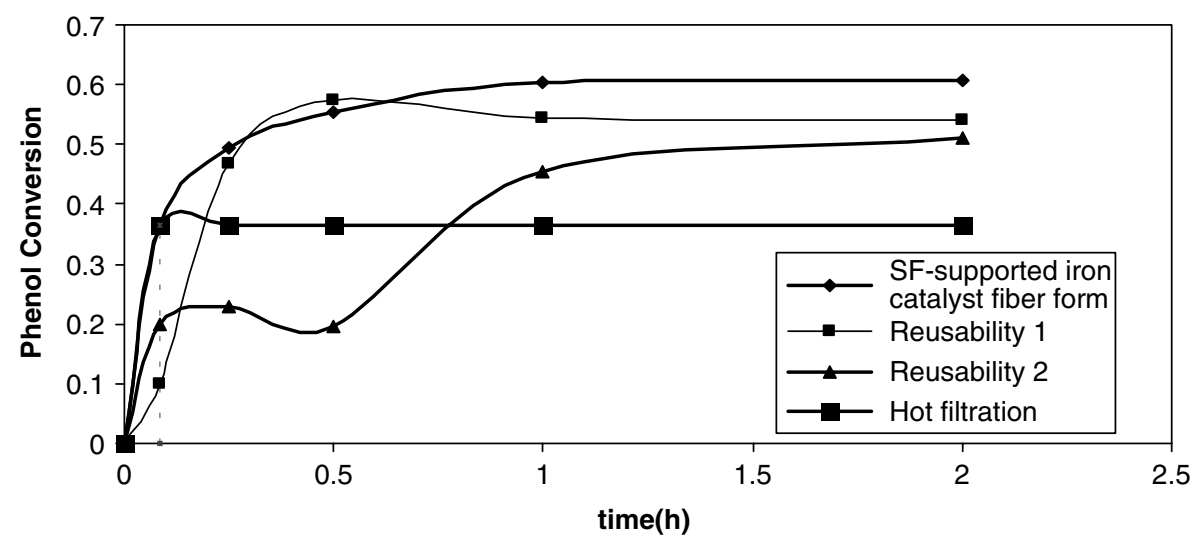

Figure 4. Phenol conversion using fiber form of catalyst (reaction conditions: phenol/ $\mathrm{H}_{2} \mathrm{O}_{2}$ molar ratio $=1,0.1 \mathrm{~g}$ catalyst, $40{ }^{\circ} \mathrm{C}$ ).

obtained by removing fiber catalyst was kept in the reactor at $40^{\circ} \mathrm{C}$ for another $2 \mathrm{~h}$ reaction. The composition of the reaction mixture was determined using HPLC at regular intervals. The data from HPLC determinations gave quantitative information about residual, catalytically active iron in solution after supported catalyst separation. Within experimental error, no increase in the amount of product was detected, proving there to be no contribution from leached species (homogeneous catalysis). In order to determine the absolute amount of the iron species dissolved in solution caused by leaching, the crude reaction mixtures were evaporated to dryness and analyzed using ICP-AES. It was shown that a trace amount of the original iron species was lost into solution during the course of a reaction. This almost negligible leaching level, which is at the limit of detection of the ICP-AES, accounts for the recoverability and reusability of the $\mathrm{Fe}-\mathrm{SF}$ catalyst.

\section{CONCLUSIONS}

A new biopolymer metal has been prepared by a simple method using fibroin and iron as raw materials, and has been found to catalyze hydroxylation of phenol to catechol and hydroquinone. The ironloaded silk fibroin catalyst can be used by cutting up the fibers with scissors and is removed easily from the reaction mixture using a pair of tweezers or by simple filtration. We believe that the present method should find broad catalytic application since the flexible and easy-handling catalyst fibers would be expected as a promising material for catalytic applications, clean energy production and material conversion process based on green chemistry. The techniques described here for preparing significantly active silk fibers are effective and economic ways of providing new catalytic materials for industrial application.

\section{ACKNOWLEDGEMENTS}

Support from the Izmir Institute of Technology, Department of Chemical Engineering, is gratefully acknowledged. We express our thanks to Professor Devrim Balköse for her valuable suggestions during this study.

\section{REFERENCES}

1 Sun J, Meng X, Shi Y, Wang R, Feng S, Jiang D, et al, A novel catalyst of $\mathrm{Cu}-\mathrm{Bi}-\mathrm{V}-\mathrm{O}$ complex in phenol hydroxylation with hydrogen peroxide. f Catal 193:199-206 (2000).

2 Xiong C, Chen Q, Lu W, Gao H, Lu W and Gao Z, Novel Febased complex oxide catalysts for hydroxylation of phenol. Catal Lett 69:231-236 (2000).

3 Yu R, Xiao F, Wang D, Liu Y, Pang G, Feng S, et al, Synthesis, characterization, and catalytic phenol hydroxylation of a novel complex oxide $\mathrm{H}_{\mathrm{x}} \mathrm{V}_{2} \mathrm{Zr}_{2} \mathrm{O}_{9} \cdot \mathrm{H}_{2} \mathrm{O}$. Catal Lett 49:49-52.

4 Maurya MR, Titinchi SJJ, Chand S and Mishra IM, Zeoliteencapsulated $\mathrm{Cr}$ (III), $\mathrm{Fe}(\mathrm{III}), \mathrm{Ni}(\mathrm{II}), \mathrm{Zn}$ (II) and $\mathrm{Bi}(\mathrm{III})$ salpn complexes as catalysts for the decomposition of $\mathrm{H}_{2} \mathrm{O}_{2}$ and oxidation of phenol. f Mol Catal A: Chem 180:201-209.

5 Liu C, Ye X and Wu Y, A novel catalyst for clean production of diphenols-ferric trisacetylacetonate/MCM-41. f Chem Tech Biotechnol 70:384-390 (1997).

6 Dubey A, Rives V and Kannan S, Catalytic hydroxylation of phenol over ternary hydrotalcites containing $\mathrm{Cu}, \mathrm{Ni}$ and $\mathrm{Al} . \mathcal{F}$ Mol Catal A: Chem 181:151-160 (2002).

7 Mastrorilli $P$ and Nobile CF, Supported catalysts from polymerizable transition metal complexes. Coord Chem Rev 248:377-395 (2004).

8 Chari MA and Syamasundar K, Polymer (PVP)supported ferric chloride: an efficient and recyclable heterogeneous catalyst for high yield synthesis of 1,5-benzodiazepine derivatives under solvent free conditions and microwave irradiation. Catal Comm 6:67-70 (2005).

9 Drelinkiewicza A, Waksmundzka A, Makowski W, Sobczak JW, Król A and Zięba A, Acetophenone hydrogenation on polymer-palladium catalysts: the effect of polymer matrix. Catal Lett 94:143-156 (2004).

10 Wei WL, Zhu HY, Zhao CL, Huang MY and Jiang YY, Asymmetric hydrogenation of furfuryl alcohol catalyzed by a biopolymer-metal complex, silica-supported alginic acid-amino acid-Pt complex. React Func Polym 59:33-39.

11 Akabori S, Sakurai S, Izumi Y and Fujii Y, An asymmetric catalyst. Nature 178:323-324.

12 Izumi Y, Studies on the silk-palladium catalyst. I. Preparation and stability. Bull Chem Soc Fpn 32:932-945.

13 Akamatsu A, Izumi Y and Akabori S, Studies on the silk-platinum catalyst. I. Its preparation and activity. Bull Chem Soc fpn 34:1067-1072.

14 Akamatsu A, Izumi Y and Akabori S, Studies on the silk-platinum catalyst. II. Bull Chem Soc fpn 35:1706-1711 (1961). 
15 Zhou Y, Chen W, Itoh H, Naka K, Ni Q, Yamane H, et al, Preparation of a novel core-shell nanostructured gold colloid-silk fibroin bioconjugate by the protein in situ redox technique at room temperature. Chem Commun 2518-2519 (2001).

16 Sajiki H, Ikawa T and Hirota K, Markedly chemoselective hydrogenation with retention of benzyl ester and $\mathrm{N}$ $\mathrm{Cbz}$ functions using a heterogeneous $\mathrm{Pd}$-fibroin catalyst. Tetrahedron Lett 44:8437-8439 (2003).

17 Sajiki H, Ikawa T, Yamada H, Tsubouchi K and Hirota K, Preparation of silk fibroin-supported $\operatorname{Pd}(0)$ catalyst for chemoselective hydrogenation. Tetrahedron Lett 44:171-174 (2003).

18 Ikawa T, Sajiki $\mathrm{H}$ and Hirota $\mathrm{K}$, Highly chemoselective hydrogenation method using novel finely dispersed palladium catalyst on silk-fibroin: its preparation and activity. Tetrahedron 61:2217-2231 (2005).

19 Vincent T, Spinelli S and Guibal E, Chitosan-supported palladium catalyst. II. chlorophenol dehalogenation. Ind Eng Chem Res 42:5968-5976 (2003).

20 Vincent T and Guibal E, Chitosan-supported palladium catalyst. 3. Influence of experimental parameters on nitrophenol degradation. Langmuir 19:8475-8483 (2003).

21 Xue L, Zhou DJ, Tang L, Ji XF, Huang MY and Jiang YY, The asymmetric hydration of 1-octene to $(S)$ (+)-2-octanol with a biopolymer-metal complex, silica- supported chitosan-cobalt complex. React Funct Polym 58:117-121.

22 Tabuani D, Monticelli O, Chincarini A, Bianchini C, Vizza F, Moneti S, et al, Palladium nanoparticles supported on hyperbranched aramids: synthesis, characterization, and some applications in the hydrogenation of unsaturated substrates. Macromolecules 36:4294-4301 (2003).

23 Balköse D, Investigation of some physico-chemical properties of natural and modified silk fibroin. Associate professorship dissertation (Doçentlik tezi), Ege University, Izmir, Turkey (1982).

24 Yamada H, Nakao H, Takasu Y and Tsubouchi K, Preparation of undegraded native molecular fibroin solution from silkworm cocoons. Mater Sci Eng C 14:41-46 (2001).

25 Altman GH, Diaz F, Jakuba C, Calabro T, Horan RL, Chen $\mathrm{J}$, et al, Silk-based biomaterials. Biomaterials 24:401-416 (2003).

26 Zhang YQ, Natural silk fibroin as a support for enzyme immobilization. Biotechnol Adv 16:961-971 (1998).

27 Sashina ES, Novoselov NP and Heinemann K, Dissolution of silk fibroin in $\mathrm{N}$-methylmorpholine- $\mathrm{N}$-oxide and its mixtures with organic solvents. Russ f Appl Chem 76:128-131 (2003).

28 Um IC, Kweon HY, Lee KG and Park YH, The role of formic acid in solution stability and crystallization of silk protein polymer. Int F Biol Macromol 33:203-213 (2003). 